\title{
Dealing with High Talent Turnover through Talent Engagement Strategies: A Study of the Hotel Sector in Thailand
}

\author{
Rudsada Kaewsaeng-on ${ }^{1}$, Mohamed Branine ${ }^{2}$, Sinini Vundla ${ }^{3}$, \\ Prachuab Tongsri ${ }^{1}$, Saqib Mehmood ${ }^{4}$ \\ ${ }^{1}$ Faculty of Humanities and Social Sciences, Prince of Songkla University, Pattani 94000, Thailand \\ ${ }^{2}$ Dean of School of Business, Law and Social Sciences, Dundee Business School (DBS), \\ Abertay University, Dundee, United Kingdom \\ ${ }^{3}$ Senior Analyst Specialist, NHS England and NHS Improvement, Manchester, United Kingdom \\ ${ }^{4}$ University of Gujrat, Gujrat, Pakistan and Superior University Lahore, Pakistan
}

\begin{abstract}
The hotel sector faces high team member turnover, incredibly talented workers who can contribute to outstanding performance and levelling world-class standards. Hotels need strategies to engage their talent effectively to maintain competitiveness. This paper used qualitative research, of which (38) semi-structured interviews were accompanied by key informants at the management level and supplemented by documentation and observation. The research revealed that effective talent engagement is linked directly to the well-known theory of effective talent management. Thus, the national culture influences talent engagement strategies. Within Thai culture, managers act as 'parents' and build strong interpersonal relationships.
\end{abstract}

Keywords -talent management, talent appointment, talent holding, hospitality management, hotel and Thailand.

DOI: 10.18421/TEM104-24

https://doi.org/10.18421/TEM104-24

Corresponding author: Rudsada Kaewsaeng-on, Faculty of Humanities and Social Sciences, Prince of Songkla University, Pattani 94000 Thailand.

Email: rudsada.k@psu.ac.th

Received: 31 July 2021.

Revised: 06 October 2021.

Accepted: 12 October 2021.

Published: 26 November 2021.

(c) BY-NC-ND (C) 2021 Rudsada Kaewsaeng-on et al; published by UIKTEN. This work is licensed under the Creative Commons Attribution-NonCommercial-NoDerivs 4.0 License.

The article is published with Open Access at www.temjournal.com

\section{Introduction}

The hotel sector, in the hospitality and tourism industry, operates in an increasingly competitive environment, and needs to contract with tests and fluctuations effectively to grow and to improve (or sustain) their reasonable advantage. Over the past decades, the sector has witnessed unprecedented growth and development in world economics. One of the challenges is the provision of services that will attract and satisfy customers [1], and the key to their success is to have talented employees (talents) who are competent and committed to doing their jobs. However, it is acknowledged that hiring and retentive the top (talents) is the utmost challenging matters. Since talent is considered as the most valuable asset to the hotel business, acquiring, developing and retaining it is a theme that needs to be explored [2]. The issue is not just about talents, but engaged and committed talents. This is because talents are a highly scarce resource, hence the Consultancy Firm McKinsey said the dialog 'war for talent' in contemporary business environments [3], [4]. In this context, engaged talents are those employees who are "attached to their work role and are absorbed by enacting it". In contrast, non-engaged talents will "not deploy their emotions, energies, and passion in conducting their work" [5]. Thus, to influence talents to be committed to their work roles and stay with the organisation, organisations need to have an effective talent engagement strategy.

Individuals with abilities are referred to as talents (ideas, knowledge, cognitive ability, skills, and potential). They may put these skills to work in the organisation to help it perform better and to complement other resources [6], [7]. Therefore, talents are often recognised as a key factor in helping organisations to remain competitive and highly 
successful. The employees are important assets who questioned CEOs of Fortune 500 companies and found that they assist in improving and increasing company performance (local and international standards).

\subsection{Statement of Purpose and Research Objectives}

This research examined how the Thai hotel sector manages and engages talented workers, how Thai culture influences the processes and strategies adopted and examines financial and non-financial incentives used to retain aptitude in the Thai hospitality (hotel and tourism) sector. The objectives of the study are: (1) to examine whether Thai culture has a significant influence on managing the talented person in the Thai hotel division, (2) to investigate how the Thai culture influences the processes and strategies of talent management and engagement, and (3) to examine how Thai hotels, use incentives (financial and non-financial incentives) in a bid to motivate, engage and retain talented talents.

\section{Literature Review}

\subsection{The Role of the Hospitality Industry (Hotel) in the Thai Economy and Society}

In both the global and Thai economies, the hotel sector is very significant. In 2017, it was found that around 6000000 works (15.5 percent of entire occupation) and added 21.2 percent to Thailand's GDP from this sector. The hotel sector dominates the hospitality and tourist business. The sector has made a significant contribution to Thailand's tourist economy and is likely to continue to do so in the future.

The Economic Community of ASEAN group (AEC), which aims to establish a unified monetary subject in Southeast Asia, offers both possibilities and dangers to the Thai hotel industry. Opportunities can arise from the increase in the number of people visiting Thailand due to the no-visa requirements for ASEAN members. More investment is envisaged to flow to Thailand which will create more job opportunities, but challenges are also envisaged. For example, there is likely to be higher competition from other ASEAN nations and from across the world. Over 600 million people will be covered by the single market, which will span ten nations with diverse ethnic and religious origins but comparable economic problems and development goals.

Thai hotels have to appeal to both regional and international visitors in order to maintain development and sustainability. This all-urement necessitates the provision of high-quality services that meet international standards. The provision and delivery of such services requires highly qualified, well-trained and talented employees at all levels. However, the way people are managed in the Thai hotels is undoubtedly influenced by the cultural values of the society in which they are operated. Thai culture is distinct and multifaceted. It is mostly formed by religious views, the majority of which are inspired by Buddhism. Consideration and genuine sacrifices for others are among Buddhism's precepts. This leads to Thais being pleasant and helpful to others, as shown by Thailand's well-known motto, "The Land of Smile". Thai smiles on the other hand, have various connotations depending on the situation. For example, Tuohy [8] classified smiling in Thai word ("Yim") express that 'I am so happy' by "Yim thang taa"; I desire to smiling but it not appear ("Yimmaiawk"). Thai cultural standards are generally accepted across the country. Kamoche [9] distinguished that these norms emphasise pleasant living such as:

- 'krengjai' It is the desire to be self-effacing, courteous, modest, and thoughtful, as well as the desire to avoid embarrassment in front of others.

- 'bunkhun' It is concerned with the reciprocity of goodwill, the demonstration of kindness, the giving and receiving of favoritisms.

- 'jai-yen' it means 'fresh heart', which is concerned with maintaining serenity and patience in social settings, as well as the need of maintaining the social.

- 'mai-pen-rai', it means frequent statement that may be used in a variety of contexts to imply "it does not matter," "never mind," and other similar phrases. To be forgiving is to avoid offending others and to not take anything too seriously in any circumstance.

- 'numjai', which stand showing concern for others.

These cultural norms and values are important in a service-oriented industry like the hotel sector. The Thai culture influences how talent management strategies are implemented and how relationships are built within Thai hotels. Kamoche [9] concluded that the wage of worker is higher and expectation of job security disheartened outlay in working out, eventually foremost to a rancorous succession of the scarcity of highly skilled labour". Furthermore, he noted the complex interplay between 'traditionalism', 'modernity' and strong cultural norms/values (such as collectivism, religious beliefs); and how this 'complex interplay' can make the management of talent extremely difficult. The view was that paternalism could be a substitute for unionism; with managers effectively playing the role of a father figure. The client-patron relationships maybe modelled along the Thai social hierarchy framework and allow "both employees and management should strive for workplace peace without having to formalise dispute-resolution processes.". 


\subsection{Understanding Talent and the Need of Talent in Thai Hotel Sector}

In defining talent, Chabault et al. [10] state that "talent is individual" and is "the first and foremost about the distinction to be made between those who have a particular talent and those who do not". The management strategies that should be adopted when managing these individuals are ones that "allow him or her to succeed better and more easily than others". Strategies for managing and engaging talent should be tailored to each person, and they can be tailored to specific sectors such as the hotel sector.

Ever since the term "the battle for talent" was coined, there has been paid responsiveness for "talent" [11]. In part, this strong emphasis on people may be attributed the circumstance that the talented employees in hotel and tourism sector is an essential resource in achieving organisational success [4], [12]. Talented employees, according to Goffee and Jones [6], may combine their potential (excellent ideas, knowledge, and abilities) with the organization's other resources to produce "added value for the organisation". Having the right people in the right place may make a huge difference in a company's success. The above issue is backed up by Michaels et al. [4], who said organisations should emphasise A players who are considered to make significant contributions to organisational success while terminating the agreements of $\mathrm{C}$ category performers whose contributions to act are below average. Goleman [13] further claimed that a person's "talent" provides value to the organisation. Their contributions have been estimated to be as much as 10 times more than those of other co-workers.

Talent is a critical factor in achieving corporate success, so organisations compete for the best employees (the so-called "war for talent"). Dries [14] came to the conclusion that the "battle for talent" is based on two fundamental assumptions:

- The conventional source of economic advantage, which is based on the information economy, is bringing up the rear superiority, while talented human being is a perpetual parameter that not possible to duplicate or pinched by rivals;

- Because of demographic changes, attracting and keeping bright individuals is becoming more challenging. In Western nations, for example, a less number of teenager employees, that linked with level of edification (and therefore the eminence of the labor force) failing to satisfy the needs of establishments. In Thailand, there is an abundance of youthful employees, but they lack the skill and learning required to occupy critical positions.

\subsection{Talent Management in hospitality industry}

According to D'Annunzio-Green [15], Talent management $\mathrm{TM}$ is a comprehensive approach to human resource planning that uses a variety of HR interventions to enhance organisational capacity and drive business objectives. Similarly, "A systematic and organised corporate strategy to the enlistment, retaining, and progress of talents inside the society". The goal is to choose individuals who will consistently provide better results". Talent management (TM) and human resource management (HRM) are not a case of the same wine in a new bottle, but rather TM is more complex than conventional human resource management and is intended to do more than simply the management of human resources [11]. TM recognises that talents provide better outcomes for the organisation for which they are employed, and that they need specialised management methods to achieve these achievements [16]. TM covers HR practices (recruitment, selection, development, engagement, and retention) [17] personnel thinking, analysis for talent fissure, recruitment and conscription, learning and supervision, retaining, talent assessment, sequence forecasting, and assessment are all processes that assist an organisation manage its people.

The emphasis is on talent pools and talent pipelines [15], and how organisations build talent pools that lead to organisational benefit at all levels via the movement of skilled employees across all levels [17]. Effective management needs TM to develop talent that fits the organisation's context and create working conditions conducive for talent engagement [10].

The narrative for effective management of 'talented workers' makes it an important function with many benefits. Because of the overall scarcity of 'talent' efficient management of talented employees are a critical role with many advantages. "It needs for working, planning and giving devotion".

\subsection{Factors Influencing Talent Engagement in the Hotel Sector}

Kahn [5] defined work engagement as to how individuals invest their energy and experiences, with the simultaneous emotional connection to the organisation and work role. The consequence of greater work engagement is better work performance [18], organisational success, and better team member retention (or organisation commitment) [19]. The ultimate result should be sustainable organisational competitiveness [20]. On the other hand, talent engagement is one of the most difficult management 
issues to solve [21]. For developing countries such as Thailand, part of the challenge is due to significant demographic changes and the lack of quality workers. Another issue is that the labour sector is increasingly becoming a worldwide market, with organisations vying for the same resources. One of the most important problems that businesses have to address is attracting and keeping top personnel; this problem is especially severe in the hotel industry owing to significant employee turnover.

Employee engagement and retention (particularly talent) is a continuous process in which the organisation seeks to keep workers for as long as possible or until the project is completed. It comprises a number of rules and procedures that encourage personnel to stay with their company for longer. Organizations have to continue to understand how to maintain their talents' happiness at the greatest level in order to achieve talent satisfaction and, therefore, engagement and retention, since talent engagement is positively linked with better product and service quality [22].

Talent engagement is important within the hotel sector because of high labour turnover and increasing competition for talents. The nature of the hospitality industry exacerbates this because of, for example, unsocial working hours, high standards of products and services, demanding customers and lack of career development [23]. A study of hotels in Thailand indicated a lack of experience among Thai owners of dealing with international hotels.

The current challenges of talent engagement and retention in the Thai hotels are related to increasing competition for talents due to the introduction of AEC, demanding customers, educational mismatch (leading to talent shortages), and lack of investment in training, which arises because of a high rate of employee revenue and job leaping; which in turn leads to scarcity of highly skilled labour.

Different employees achieve employee satisfaction in the hospitality industry under different situations. Putra et al. [24], found that employees in the hospitality sector were enthused by monetary incentives (e.g., a fair-minded pay compendium) and favourable working circumstances (e.g. working hours per week). According to Setti and Argentero [25] the biggest satisfaction and on talent engagement and retention is the level of pay. However, while this is generally true when considering the type of employees in hospitality, there are many other tangible and intangible factors that motivate talents to be committed to their jobs in this sector. As Tymon et al., [26] argued, nonmonetary rewards should also be considered to motivate talents. Similarly, Gibbons [27] said that intrinsic motivation (e.g., a positive connection with one's boss) is more essential than extrinsic incentive (e.g., money). Lehmann [28] came to the conclusion that skills should be rewarded with money, as well as social acknowledgment and personalised instruction and development. Employee loyalty, trust, perceptions of justice, fulfilling commitments, and satisfying responsibilities are all affected by having the appropriate motivation.

Talented workers, according to D'Annunzio-Green [15], go around after 2-3 years if they do not get rapid advancement chances as promised during the recruiting period. Praise and feedback are found to have significant influence on talent retention. Thorne and Pellant [29] stated that "what talents despise overlooked or, inferior, actuality forced to remain in box by the capacity to operate in a variety of settings". Acknowledgement is an important aspect of motivating talents. Talents who had been officially recognised as talents in the organisation were more likely to be encouraged to remain than to leave, according to research by Björkman et al. [30]. Extrinsic (e.g., a benefit of accommodation) and intrinsic (e.g., praise for excellent work) incentives may both be used to give recognition [26]. In addition, seven variables that are likely to enhance talent retention and engagement. These include remuneration and gratitude for a job done, difficult work; learning opportunities; positive connections with co-workers; acknowledgement of skills and working ability; excellent balancing job assistance; and effective internal connection. Uygulamasi [31] discovered that confidence in the organization's brand, professional growth possibilities, a fair compensation structure, and demanding and engaging work all impacted talent retention. As the number of hotels increase in Thailand, brand image becomes one of the factors that positively influences hotel staff's work commitment.

\section{Methodology}

\subsection{Approach and Sampling}

This study used a qualitative method of data collecting and analysis because it seeks to explore a topic in detail, comprehend the research problem in a real-world setting, and determine if what is occurring can be ascribed to a theory [32]. Purposive and snowball sampling was used to choose the sample, with the method first used to get access to the target hotels. Purposive sampling, as stated by Berg and Lune [33], is based on the true goal of the study, which is to find, gain, and comprehend a certain phenomenon (e.g. purpose in gaining views and experiences from key positions). 


\subsection{Research Question and Instrument}

The research used open-ended questions to gather data. The interviews focused on the problems and challenges that participants faced in managing talents, particularly talent engagement and retention in their hotels. All the participants were asked the same open-ended questions which were related to the research objectives.

The research instrument for this study was developed on qualitative data analysis approach to investigate the association between talent management and retention approaches in Thailand hotels [32]. The content analysis of the survey transcripts was conducted to identify the significant themes and motives described by interviewees. Data triangulation was achieved through using direct observation and documentation data; that is, emerging themes were corroborated using other instruments such as direct observation and documentation review.

The research instrument was separated into two parts. Firstly, the research instrument was created to investigate the association between the significance of Thai culture in hospitality industry and talent management strategies applying [32] qualitative theory. Secondly, the research instrument content analysis was used to determine themes such as repayment, 'parenting leader' and 'karma'. The thematic analysis of the research instrument aimed to identify and describe the patterns, themes and approach strategies on talent management and retention. The research instrument comprised five themes, including How do the participating hotels define talent?; What are the criteria for identifying skilled employees?; What variables affect the identification of talented workers?; What difficulties do hotels confront when it comes to personnel management?; How do Thai Hotel Association (THA) member hotels manage talent to meet the challenges?

\subsection{Sample}

This study adopted a qualitative approach in the collection and analysis of data because it seeks to study a topic thoroughly, to comprehend the research problem in a real-world setting, and to determine if what is occurring can be ascribed to a theory [32]. The preliminary sample was chosen using purposive and snowball sampling, with the technique to begin with engaged for the purpose of choosing the hotel sector for the research study.

Participants had been selected on the basis of three (3) criteria viz. HR decision making process, hotel star-rating ( $4 *$ and $5 *$ hotels), and hotel size (more than 100 rooms). Initially, emails were sent out to
100 hotels (4* and $5^{*}$ hotels) that would be the affiliates to Thai hotel organisation. However, among them, individually four (4) hotels staffs responded and were eager to take part in the research; and this involved seven (7) participants (Table 1). The researcher contacted the hotels that originally took part in the study to suggest additional individuals who matched the requirements (snowballing technique). Finally, the total sample data were collected from key staff members in 29 selected fourand five-star hotels in Bangkok, Pattaya and Phuket. These hotels were members of THA.

At each site, an open-ended questionnaire on talent engagement and retention of talent in hotels was used to collect the samples. The survey questionnaire was addressed 3 significant parts. The first part examined the management of talents in hotel to counter the challenges in modern day Thailand hotel industry. The second part enquired the effect of Thai culture on the talent management process in Thailand hotel industry. The third part inquired the distinct usage of talent management in the Thailand hotel industry.

Through the snowballing effect, participating key staff members in the selected hotels were contacted by electronic mail. The purpose of the research was to recommend other participants. However, the data which did not fall under the selection criteria were discarded from the study resulting in 38 observations from semi-structured face to interviews during the period of study.

The final sample was four- and five-star hotels that covered most of Bangkok, Pattaya and Phuket; however, no choices were proposed by other respondents using the snowball effect sampling technique, no responses were extracted in the Northern region. The profiles of the participants are presented in Table 1.

\subsection{Data Analysis}

The final sample consisted of thirty-eight interviews, thirty-three (33) of which were recorded and transcribed. Meanwhile, written notes on the other five participants were prepared. Each interview lasted about 1.5 hours and took conducted in a hotel environment, allowing the interviewer to make some observations. Furthermore, observation data and documentation were collected based on the given themes. For all cases, the rights and confidentiality of participants were observed. The data were analysed using the thematic analysis technique to describe the perceived patterns, themes, categories, bias and meaning in line with the suggestions [33].

Further, the research instrument content analysis was used to determine themes such as repayment incentives, 'parenting leader' and 'karma'; and identify talent management and retention strategies. 
Table 1. Profiles of participants

\begin{tabular}{|c|c|c|c|c|c|}
\hline Position & Code & Age & $\begin{array}{c}\text { Initial or Main } \\
\text { (M) Study }\end{array}$ & Gender & Experiences/Years \\
\hline \multirow{8}{*}{$\begin{array}{c}\text { General Managers, } \\
\text { Holders, Dwelling } \\
\text { managers, } \\
\text { and Topmost Officials }\end{array}$} & GM1 & 37 & $\mathrm{M}$ & Male & 12 \\
\hline & GM2 & 52 & M & Male & 25 \\
\hline & GM3 & 56 & $\mathrm{M}$ & Male & 40 \\
\hline & GM4 & 55 & Initial & Male & 25 \\
\hline & GM5 & 55 & $\mathrm{M}$ & Male & 30 \\
\hline & GM6 & 32 & M & Female & 5 \\
\hline & GM7 & 45 & M & Female & 15 \\
\hline & GM8 & 55 & $\mathrm{M}$ & Male & 20 \\
\hline \multirow{18}{*}{$\begin{array}{l}\text { Human Resource } \\
\text { Directors/Manager }\end{array}$} & HRM1 & 42 & Initial & Female & 10 \\
\hline & HRM2 & 37 & M & Female & 6 \\
\hline & HRM3 & 45 & Initial & Male & 16 \\
\hline & HRM4 & 34 & $\mathrm{M}$ & Female & 7 \\
\hline & HRM5 & 42 & M & Female & 12 \\
\hline & HRM6 & 39 & M & Female & 10 \\
\hline & HRM7 & 48 & M & Male & 20 \\
\hline & HRM8 & 42 & $\mathrm{M}$ & Male & 15 \\
\hline & HRM9 & 43 & Initial & Male & 10 \\
\hline & HRM10 & 38 & $\mathrm{M}$ & Male & 10 \\
\hline & HRM11 & 39 & M & Male & 13 \\
\hline & HRM12 & 37 & M & Female & 10 \\
\hline & HRM13 & 36 & $\mathrm{M}$ & Male & 10 \\
\hline & HRM14 & 38 & Initial & Male & 7 \\
\hline & HRM15 & 45 & $\mathrm{M}$ & Male & 10 \\
\hline & HRM16 & 42 & M & Feale & 10 \\
\hline & HRM17 & 42 & M & Male & 5 \\
\hline & HRM18 & 49 & M & Male & 9 \\
\hline \multirow{12}{*}{ Line Managers } & LM1 & 38 & Initial & Female & 14 \\
\hline & LM2 & 42 & $\mathrm{M}$ & Male & 15 \\
\hline & LM3 & 45 & $\mathrm{M}$ & Female & 18 \\
\hline & LM4 & 38 & M & Female & 10 \\
\hline & LM5 & 42 & M & Female & 15 \\
\hline & LM6 & 37 & M & Male & 8 \\
\hline & LM7 & 37 & $\mathrm{M}$ & Male & 12 \\
\hline & LM8 & 35 & $\mathrm{M}$ & Female & 10 \\
\hline & LM9 & 45 & Initial & Male & 17 \\
\hline & LM10 & 39 & $\mathrm{M}$ & Male & 10 \\
\hline & LM11 & 35 & M & Female & 6 \\
\hline & LM12 & 42 & M & Female & 15 \\
\hline
\end{tabular}

\section{Study Findings}

\subsection{Thai Culture Influence on Management of Talent in the Thai Hospitality Industry}

The work partially confirms the objectives as it reveals that the Thai culture is not the only significant factor influencing the practice of talent management in the participating hotels. The influence of global competition and international hospitality standards are more significant than that of national culture. However, it should be noted that culture impacted the overall leadership and management of the hotels studied rather than specifically on talent management. For example, the respondents often used words like 'collective' and 'family' to describe the type of leadership in their hotels. The majority of general managers and owners said that all of their workers were treated like members of their society, and treated as such. As an example, GM1 said:

"We treat our employees as if they were members of our family; this is the owner's policy since he considers all employees to be his or her sons or daughters... If we take care of them well, it will make a significant impact in their work...they will become more devoted to our organisation".

GM2 stated: "the hotel owner treats us as his children...we adore and respect him as a father... he is an easy-going man and stands on his subordinates' side, always like families should..."

LM1 said, "We remain here like a bonding. Recruiting new members (inside/outside) has to accept and adapt their manner in ability to assimilate in with us". Consequently, GM4 said that "excellent employees who confidence and promise to working 
for the specific group must strive to modify expertise and understandings to adjust and function effectively." I believe on completely dedicate on organization's purpose, they will be better employees".

Repayment, 'parenting leader', 'karma' etc., were among some of the themes that were mentioned by the respondents in their description of their management of human resources but there was no clear evidence of cultural values influencing talent engagement and retention. On the contrary, there was more concern about the influence of competition and customer service on the need to engage and retain talent in the hotels industry. For example, HRM1 explains that "our primary job at the hotel is to serve and delight the clients." And, without a doubt, the primary duty of talent should be to tremendously please the customers".

\subsection{Thai Culture Influences the Processes and Strategies of Talent Management and Engagement}

The HRM18 claimed, “...We must preserve the quality; talents here should understand that its customer is leader, and they must use all possible to keep them smile; else, our branding will suffer, and the company's long-term viability may be threatened.".

GM1 agreed, saying, "Our visitors anticipate a much for both the money they've spent, and it's our imperative to support it the best trip they've ever had".

The remark that follows from GM3 nicely explains this viewpoint. "All talents should be service-minded first and foremost," he added. Then keep a good physical look (for example, grooming that is neat and clean);... Because hotels offer 24-hour service, it is also necessary to be able to work shifts. They should also be honest, diligent, and ready to learn. We don't mind those who have no expertise as far as they can acquire; however, they should have some idea of what they're doing... the ability to communicate".

GM5 went on to say that if organisations want to achieve the worldwide level, they have to have a sufficient number of skilled people to stay competitive. He said that "We must remain having guidance even as hospitality sector will become more competitive owing to global economic competition". We fight not only with local hotels, but with a broad range of international enterprises. To compete in the market, we need drivers (talent) who can think globally".

\subsection{Thai Hotels, Use Incentives (Financial and non-Financial Incentives) in a Bid to Motivate, Engage and Retain Talented Talents}

There are many incentives (financial and nonfinancial incentives) that Thai hotels use to motivate, engage and retain talented talents; financial rewards remain the biggest incentive used in talent retention. Table 2 reveals that different hotels adopted different reward approaches to motivate and retain their employees. The emerging themes were corroborated using other instruments such as direct observation and documentation review to achieve data triangulation.

Furthermore, it categorises a variety of tangible and intangible rewards, ranging from pay to building internal/supervisory connections that should be strong, and the talent pipeline should be built. (creating career pathways), pleasing the executive promise, providing autonomy, and elasticity in decision-making, developing employer branding, and providing appropriate and adequate compensation.

Table 2. Talent Engagement Techniques

\begin{tabular}{llll}
\hline Theme (Ranking from high to low) & $\begin{array}{l}\text { Semi-structured } \\
\text { interviews }\end{array}$ & Documentation & Observation \\
\hline $\begin{array}{l}\text { Providing appropriate pay and other } \\
\text { benefits }\end{array}$ & $\checkmark$ & $\checkmark$ & $\checkmark$ \\
$\begin{array}{l}\text { Building good internal relationships } \\
\text { Building the talent pipeline (creating }\end{array}$ & $\checkmark$ & $\checkmark$ & $\checkmark$ \\
career pathways) & $\checkmark$ & $\checkmark$ & N/A \\
$\begin{array}{l}\text { Fulfilling organisational promises } \\
\text { Autonomy and flexibility in the decision- }\end{array}$ & $\checkmark$ & N/A & N/A \\
making process & $\checkmark$ & N/A \\
$\begin{array}{l}\text { Building employer branding } \\
\text { Promoting and selling the organisation's }\end{array}$ & $\checkmark$ & $\checkmark$ & $\checkmark$ \\
vision & $\checkmark$ & $\checkmark$ & N/A \\
$\begin{array}{l}\text { Providing appropriate and adequate } \\
\text { training }\end{array}$ & $\checkmark$ & $\checkmark$ & $\checkmark$ \\
$\begin{array}{l}\text { Recognising and valuing talents } \\
\text { Promoting \& selling the organisation's }\end{array}$ & $\checkmark$ & $\checkmark$ & N/A \\
$\begin{array}{l}\text { vision to new and current workers } \\
\text { Putting the right people to take the role of } \\
\text { managing talent }\end{array}$ & $\checkmark$ & N/A & N/A \\
\hline
\end{tabular}

Pay and other tangible benefits (e.g., transportation, lodging, and insurance) were unanimously cited as the most significant incentives to recruit talent inside participating hotels by all respondents. While the fundamental salary levels at the participating hotels did not very much, the major variances are the service charges and incentives that workers earn. Participants agreed that developing effective inner connections enhance personnel retention and engagement between management and colleagues. The majority of general managers and hotel owners shared this perspective. who felt that various employee engagement events, such as organising staff birthday celebrations and New Year's Eve parties, helped build internal connections. Another method utilised by participating hotels to engage and retain people was to build a talent pipeline or create career paths for talent engagement. 
The majority of participants felt that developing a conduit of talents enables the company to have a "heelix" of skills that can be quickly utilised to fill gaps within the organisation. The benefit of developing a talent pool from inside the organisation is that the talent is already well-versed in the organization's culture.

The majority of participants said that keeping organisational promises (doing what you said you would do) was critical to engaging and retaining talent. Compensation (e.g., base salary, extra pay, incentives, subscriptions, transportation allowances, healthcare, career, and leisure are all examples of compensation) was one of the organisational promises that had to be kept. Another incentive that participants thought was essential for talent engagement and retention was having autonomy and flexibility in decision-making, although this depends on the employee's position in the organisation. Everyone agreed that people with professional abilities and skills should be allowed considerable autonomy in their job. Employer branding is an attempt by organisations to constantly remind 'potential talents' about them while also making their brand name memorable and appealing. Potential talent would want to work with them as a result of this good exposure. In addition to employer branding, which is primarily focused on recruiting prospective workers, presenting and selling the organization's vision and objectives was said to be critical for engaging and keeping talent. Some respondents saw this technique as one of the most effective means of persuading employees to remain with the company.

One of the incentives utilised by the participating hotels to attract and retain talent was sufficient training. The majority of participants said that they assist new and current workers in learning new working methods by implementing frequent and ongoing training programmes. For example, LM7 claimed that they provided training classes to all employees in order to keep them up to speed on their duties. "We offer an on-the-spot performance appraisal orientation for new workers, and fundamental courses for existing staffs," he said, adding, "we mainly hire people from inside, so we have to educate them to keep them up to date and ready for promotion".

Recognising and valuing talents for their performance and contribution to the organisation were reported as important aspects of influencing talents to stay in the organisation. It was regarded as a highly important means of motivating talent to feel good about the hotel. However, the level and form of recognition differed among the hotels, and it is especially based on the ownership structure. Different hotels have different situations and adopt different talent recognition approaches. For example, the international and Thai hotel chains were more financially able to support recognition schemes than individual Thai hotels. Some participants stated that "placing the appropriate people in charge of employee engagement" is likely to increase talents engagement and retaining.

\section{Discussion}

The study demonstrates that Thai hotels employ various talent engagement and retention approaches. The approaches adopted fall into four main categories: talent recruitment methods, talent pipelines, talent motivation approaches, and building talent management mindsets. The approaches mark the end-to-end talent management process among Thai hotels and are interlinked. This multifaceted talent management approach among Thai hotels shows that the main concern is not just talents but also engaged and committed talents [34].

Talent motivation approaches based on extrinsic incentives like pay and allowances were more influential than intrinsic incentives such as recognition or work. This can be attributed to current economic difficulties where employees need tangible rewards (money) rather than intangible rewards. The literature review revealed that the hotel sector is now a worldwide organisation competing for the same scarce resource [3]. It is little wonder then that Thai hotels are feeling pressure to offer financial incentives.

While financial incentives were important, the study also affirms that non-financial incentives are important. Relationships and communication, for example, play a critical role in encouraging employees to remain in their present positions. It is suggested that hotel managers foster a work atmosphere that fosters positive internal connections. For example, periodic informal gatherings and activities like birthday parties, New Year's Eve parties, sports days, and so on that bring workers of all levels and statuses together are required to foster stronger internal connections. Praise for and recognition of good performance and high achievements can help to increase internal relationships. Employer branding can be used to motivate talents to join the organisation. The Thai hotels have to build an international reputation in the hospitality industry and establish themselves as the providers of high-quality goods and services in the region to attract and retain talents.

The results also show that closely linked to talent motivation approaches is the need to have clear career progression pathways (talent pipelines), which appropriate talent recruitment methods should underpin. Talent recruitment methods based on non- 
traditional methods (Facebooking, Twitter, online submission, institutional webpage) serve a significant influence in reaching and attracting potential talents compared to traditional talent recruitment methods (e.g. newspapers, job magazines, local radio). While these findings might not be new ideas within the context of Western economies, Thai hotels are only beginning to understand that the increasing need and use of social media as job hunting tools among job seekers and between job seekers and recruiters. This is a new approach, consolidating "the word of mouth and recommendations" which are traditionally popular recruitment methods in the Thai labour market. Furthermore, clear career progression pathways help the engagement and retention of talents. Managers should create an environment where employees have an opportunity to learn and grow, and this will in turn motivates talents to stay in the organisation. While, the increasing mobility of talents has enabled some 'rich' hotels to attract (buy) ready-made talents using competitive reward packages, this study has confirmed that 'buying talents' from outside is not as effective as having home-grown talents. It is recommended that the Thai hotels should provide opportunities of promotion and allow talents to learn and grow from within through having clear progression career pathways.

Kamoche [9] observed that there is a complex interplay between 'modernity' and strong cultural values (such as the Thai's collectivism beliefs); and commented how this 'complex interplay' can make the management of talent extremely difficult. This was exemplified by the view among Thai hotels that paternalism could be a substitute for unionism; with managers effectively playing the role of a father figure which is influenced by Buddhist beliefs. However, this was not always straightforward given that some hotels were multinationals, and therefore while the middle management might have been predominantly Thai and therefore more inclined to put into practice such ideas; however, such ideas would be harder implement if the strategic direction comes from non-Thais executive managers and is completely different. The study does not only confirm the complex interplay between 'modernity' and strong cultural values; but also, the complex (and at times competing) interplay between offering financial incentives and non-financial incentive as explored above. Even though Thai culture plays an important role among Thai hotels, however the influence of global competition and international hospitality standards are more significant than that of national culture. The culture had an impact on the overall leadership and management of the hotels studied rather than specifically on talent management.
The use of talent pathways ensures continuity within the workforce. It means that engaged talents are not only those who are "attached to their work role and are absorbed by enacting it", but also those who will "deploy their emotions, energies, and passion in conducting their work" [5]. However, the building of a talent pathway might lead to the danger of inbreeding. To avoid the dangers of inbreeding of employees with limited international and crossindustry exposure, the Thai hotels should have opportunities for international training and development through internal/external training courses. Furthermore, Thai hotels have to build an international reputation in the hospitality industry and establish themselves as the providers of highquality goods and services in the region to attract and retain talents.

\section{Conclusion}

The research concludes that Thai culture influences the management and leadership processes in general. However, when it came to the management of talents, international standards and business incentives were more influential. For example, the uses of extrinsic incentives like pay were more significant than 'the good smile'. However, it was found that the participants particularly cited good relationships as being among the primary concerns of Thailand hotel management. This finding confirms previous studies about the need to maintain good relationships within the organisation because of their commitment, motivation, and talent retention.

The research discovered that talent management methods employed in Thai hotels to attract and motivate people are intimately connected to core Talent acquisition, as well as skills development, are examples of strategy implementation, incentives and compensation, and employee relations. The procedure begins with the recruiting stage and is intensified after the organisation hires the talents. These results are consistent with the talent management literature. For example, Stahl et al. [17] found that investment in all HR activities/functions is strongly linked to successful talent management.

According to the findings of this study, the hotel sector in Thailand 'expenditures' a mix of fundamental and split methods to engage (inspire) talents, with split tactics dominating. This finding affirms previous research by Tymon Jr et al., [26] that reported the use of a combination of both fundamental and split incentives to attract and retain talents; and research as mentioned by Horwitz et al., [35] which discovered that the hotel sector used extrinsic motivators to recruit talent, such as competitive compensation and other perks. 
Furthermore, this study has found that building a talent pipeline to engage talents by giving them prospects to acquire and growing within the association is a significant incentive for appealing and encouraging talents to remain in the Thai hotels despite the increasing competition for the talented hospitality sector. Talent workers stay with the sector, understanding that there will be chances to improving and growing.

It can be concluded from the research findings that since the nature of work in the hotels industry has become more and more standardized, and it has to meet international standards in the provision of day to day services, the management of talents in the Thai hotels cannot be any different from that of other hotels worldwide. However, while aspiring to apply an international approach to talent management attention should be given to aspects of the Thai culture in employee relationships. The study is expected to provide researchers and practitioners of talent management with an understanding of the challenges of talent engagement and retention in the Thai hotels.

\section{Implications}

The research adds to the understanding of talent, particularly applying in the hospitality sector. Experts may include this conceptualization into managerial activities, as well as in establishing talent criteria inside the organisation, such as recruiting and selection criteria. Furthermore, the study will increase practitioners' knowledge of recruiting methods and how to more successfully attract their target skills. The study has shown us that, although conventional methods (broadcasting media, professional site, localized transistor) would be employed, unconventional media or else social networking sites (Facebooking, Line, company webpage) can serve a significant part. Customers and employees may benefit tremendously from social networking sites, which include enlistment of skilled staffs. As a result, in today's technologically advanced worldwide, social media is highly present methods for labelling an organisation and making it appealing to prospective quality employees.

Finally, the research could also enable the company in selecting motivational methods in order to successfully recruit talent. The strong implication is, therefore, that managers and decision makers in the hospitality industry should focus on practices that impact effective commitment, and also, on having appropriate talent recruitment and development processes that greatly help meet the talent retention objectives.

\section{Future Research and Limitations}

Conducting this research study has been a challenging experience, and in doing so, there have been several methodological and theoretical limitations. Qualitative data were collected using semi-structured interviews with the hotels' managers and not with the workers (possible talents). It means that the study relied on the managers' perspective rather than the views of both. This is because it was not possible to identify who the talents were in the hotels studied, and there was no time to do so during the limited period of this research.

Future studies will benefit from collecting data through interviews (qualitative) with decision-makers (managers) and questionnaires (quantitative) with identified talents. Focusing on the issues from a team member's perspective would build a better understanding of the process of talent engagement within hotel businesses. This study was only conducted among hotels in Thailand, limiting the generalisation of the results to other sectors and industries. Future research could involve different sectors of the economy and even better if a comparative study is conducted between different sectors in different countries.

\section{References}

[1]. Amissah, E. F., Gamor, E., Deri, M. N., \& Amissah, A. (2016). Factors influencing employee job satisfaction in Ghana's hotel industry. Journal of Human Resources in Hospitality \& Tourism, 15(2), 166-183.

[2]. Choi, Y., \& Dickson, D. R. (2009). A case study into the benefits of management training programs: Impacts on hotel employee turnover and satisfaction level. Journal of Human Resources in Hospitality \& Tourism, 9(1), 103-116.

[3]. Axelrod, B., Handfield-Jones, H., \& Michaels, E. (2002). A new game plan for C players. Harvard Business Review, 80(1), 80-90.

[4]. Michaels, E., Handfield-Jones, H., \& Axelrod, B. (2001). The war for talent. Harvard Business Press.

[5]. Kahn, W. A. (1990). Psychological conditions of personal engagement and disengagement at work. Academy of management journal, 33(4), 692724.

[6]. Goffee, R., \& Jones, G. (2007). Leading Clever People. Harvard business review, 85(3), 72-142.

[7]. Kaewsaeng-on, R., Kane, K. J., \& Vundla, S. (2015). Talent-its application to the Thai hospitality industry. International Journal of Innovation, Management and Technology, 6(6), 367.

[8]. Tuohy, T. (2013). Watching the Thais. Booksmango.

[9]. Kamoche, K. (2000). From boom to bust: The challenges of managing people in Thailand. International Journal of human resource management, 11(2), 452-468. 
[10]. Chabault, D., Hulin, A., \& Soparnot, R. (2012). Talent management in clusters. Organizational Dynamics, 4(41), 327-335.

[11]. Iles, P., Preece, D., \& Chuai, X. (2010). Talent management as a management fashion in HRD: Towards a research agenda. Human Resource Development International, 13(2), 125-145.

[12]. Yao, T., Qiu, Q., \& Wei, Y. (2019). Retaining hotel employees as internal customers: Effect of organizational commitment on attitudinal and behavioral loyalty of employees. International Journal of Hospitality Management, 76, 1-8.

[13]. Goleman, D. (2006). The socially intelligent. Educational leadership, 64(1), 76-81.

[14]. Dries, N. (2013). The psychology of talent management: A review and research agenda. Human Resource Management Review, 23(4), 272-285.

[15]. D'Annunzio-Green, N. (2008). Managing the talent management pipeline: Towards a greater understanding of senior managers' perspectives in the hospitality and tourism sector. International Journal of Contemporary Hospitality Management, 20(7), 807-819.

[16]. Hana, U., \& Lucie, V. (2015). Investigating Talent Management Philosophies. Journal of Competitiveness, 7(3), 3-18.

[17]. Stahl, G., Björkman, I., Farndale, E., Morris, S. S., Paauwe, J., Stiles, P., ... \& Wright, P. (2012). Six principles of effective global talent management. Sloan Management Review, 53(2), 2542.

[18]. Karatepe, O. M. (2013). High-performance work practices and hotel employee performance: The mediation of work engagement. International Journal of Hospitality Management, 32, 132-140.

[19]. De Boeck, G., Meyers, M. C., \& Dries, N. (2018). Employee reactions to talent management: Assumptions versus evidence. Journal of Organizational Behavior, 39(2), 199-213.

[20]. Hekman, A., \& Lashley, C. (2017). Workers in the luxury hospitality industry and motivation-the influence of gender, age and departments. Research in Hospitality Management, 7(2), 115-120.

[21]. Murray, W. C., Elliot, S., Simmonds, K., Madeley, D., \& Taller, M. (2017). Human resource challenges in Canada's hospitality and tourism industry. Worldwide Hospitality and Tourism Themes, 9(4), 391-401.
[22]. Walsh, K., \& Taylor, M. S. (2007). Developing inhouse careers and retaining management talent: What hospitality professionals want from their jobs. Cornell Hotel and Restaurant Administration Quarterly, 48(2), 163-182.

[23]. Sheehan, M., Grant, K., \& Garavan, T. (2018). Strategic talent management: a macro and micro analysis of current issues in hospitality and tourism. Worldwide Hospitality and Tourism Themes, 10(1), 28-41.

[24]. Putra, E. D., Cho, S., \& Liu, J. (2017). Extrinsic and intrinsic motivation on work engagement in the hospitality industry: Test of motivation crowding theory. Tourism and Hospitality Research, 17(2), 228241.

[25]. Setti, I., \& Argentero, P. (2011). Organizational features of workplace and job engagement among Swiss healthcare workers. Nursing \& Health Sciences, 13(4), 425-432.

[26]. Tymon Jr, W. G., Stumpf, S. A., \& Doh, J. P. (2010). Exploring talent management in India: The neglected role of intrinsic rewards. Journal of World Business, 45(2), 109-121.

[27]. Gibbons, J. M. (2006). Employee engagement: A review of current research and its implications. Conference Board.

[28]. Lehmann, S. (2009). Motivating talents in Thai and Malaysian service firms. Human Resource Development International, 12(2), 155-169.

[29]. Thorne, K., \& Pellant, A. (2007). The essential guide to managing talent: How top companies recruit, train, $\&$ retain the best employees. Kogan Page Publishers.

[30]. Björkman, I., Ehrnrooth, M., Mäkelä, K., Smale, A., \& Sumelius, J. (2013). Talent or not? Employee reactions to talent identification. Human Resource Management, 52(2), 195-214.

[31]. Uygulamasi, Y. Y. P. B. M. (2014). An Application on the Brand of Talent Management Perspective. Journal of Yasar University, 9(35), 60996260.

[32]. Creswell, J. W., \& Poth, C. N. (2016). Qualitative inquiry and research design: Choosing among five approaches. Sage publications.

[33]. B. L. Berg., (1995). Qualitative Research Methods for the Social Sciences, Boston:Bacon \& Allyn.

[34]. Adler, A. (2013). The practice and theory of individual psychology (Vol. 133). Routledge

[35]. Horwitz, F. M., Heng, C. T., \& Quazi, H. A. (2003). Finders, keepers? Attracting, motivating and retaining knowledge workers. Human resource management journal, 13(4), 23-44. 